\title{
DEL FETICHE A "LA COSA": LA IMPORTANCIA DE LOS OBJETOS EN OCIO DE FABIÁN CASAS
}

\author{
Felipe Adrián Ríos Baeza \\ Universidad Anáhuac, Campus Querétaro (México) \\ felipe.rios@anahuac.mx
}

\begin{abstract}
Resumen: Empleando ciertas nociones del psicoanálisis, como la de "fetiche", "fantasma" y "das Ding", en este ensayo se analizará la narrativa del escritor argentino Fabián Casas, teniendo a su novela Ocio (2000) como centro para poder afirmar lo siguiente: para sus protagonistas, la presencia de ciertos objetos cobra suma importancia, ya que estos funcionarán al menos en dos niveles: uno empírico y fenoménico (haciendo que los personajes habiten de manera más amable ciertos espacios ya dados) y otro "sublime" (actuando como fetiche, es decir, como fachada para desviar de sí un contenido más complejo y dañino, asociado a lo que Jacques Lacan denomina "lo Real"). De esta manera, se descubrirá un eje esencial de su literatura: que los objetos ayudan a dar rodeos para no enfrentar algo que, inevitablemente, acabará manifestándose y que tiene que ver siempre con los afectos primarios.
\end{abstract}

Palabras clave: Fabián Casas, fetiche, das Ding, literatura argentina, narrativa contemporánea.

\section{FROM FETISH TO "THE THING": THE IMPORTANCE OF OBJECTS IN FABIÁN CASAS' OCIO}

\begin{abstract}
Using certain notions from psychoanalysis, as "fetish", "phantom", and "das Ding", this paper will focus on the analysis of the Argentinian writer Fabián Casas' narrative, considering his novel Ocio (2000) as the centerpiece to declare the following: the presence of some items has extreme importance for the characters, because they will function in, at least, two levels: an empirical and phenomenal (helping the characters inhabit some given spaces in a friendlier way), and other "sublime" (acting as a fetish; as a façade to get more complex and harmful content away from them, associated to what Jacques Lacan denominates as "the Real"). This way, an essential axis to his narrative will be discovered: objects help beating around the bush to avoid facing something that, inevitably, will end up coming out, and which always is related to primary affections.
\end{abstract}

Keywords: Fabián Casas, fetish, das Ding, Argentinian literature, contemporary narrative.

DOI: $\underline{\text { https://doi.org/10.24029/lejana.2018.11.255 }}$ 
Recibido: el 6 de junio de 2018

Aceptado: el 20 de agosto de 2018

Publicado: el 22 de octubre de 2018 
Dos novelas, un libro de cuentos, un relato infantil, nueve poemarios, cuatro volúmenes de ensayos y un tomo de sus primeros diarios dan cuenta de la visible trayectoria del escritor argentino Fabián Casas (Buenos Aires, 1965). Aun así, para una buena porción de los lectores latinoamericanos y europeos, Casas es todavía un desconocido, solo un nombre asociado, en un simplista ejercicio metonímico, al de Rodolfo Fogwill, Washington Cucurto, Leila Guerriero y otros de la llamada generación "de recambio cultural" en Argentina.

A comienzos de la década de 1990, su propósito inicial (igual que el de Borges y el de Bolaño) fue consagrarse como poeta, publicando Otoño, poemas de desintoxicación y tristeza (1988), Tuca (1990) y El salmón (1996), libros que provocaron cierta repercusión en circuitos bonaerenses de exquisitez intelectual. Su proceder, de hecho, fue catalogado por algunos críticos

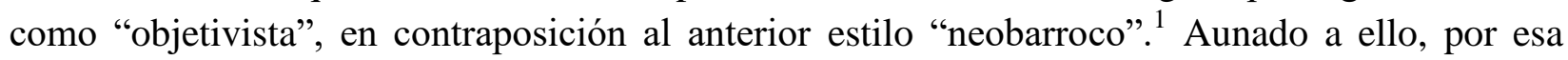
época probó suerte en el periodismo. Además de fundar, en 1990, la revista 18 Whiskys con poetas de su generación, como Daniel Durand, Eduardo Ainbinder y Darío Rojo, colaboró con Perfil, Página/12 y La Nación, escribiendo crónicas vigorosas en las que, como en sus poemas, se hablaba a partes iguales de Francis Ford Coppola y Néstor Perlongher, de meditación zen y Led Zeppelin, de Schopenhauer y Luis Alberto Spinetta. Dicha mixtura, que podría parecer simplemente, y por época, la alineación de Casas con la estética posmoderna (la conjunción de la high y la low culture en un mismo espacio de significación), ha articulado un eje transversal en su obra, imprescindible de volver a hacer notar para entender cabalmente su propuesta. Ya lo señaló el crítico Daniel Nimes: "Ese cruce, que Casas viene haciendo desde Tuca [...] se ha convertido en un modus operandi bien propio de la llamada generación del noventa: los cruces son constantes y desjerarquizantes: no hay crítica o valorización/desvalorización de los elementos, sino que ambas esferas permiten un cruce dialéctico" (2010: 1825). Y más adelante, el crítico agrega algo fundamental para este trabajo: "Lo que cabría preguntarse aquí es qué sujeto imaginario se construye en la poesía de Fabián Casas, a través de ese ritmo y esa sintaxis que hemos llamado narrativa" (2010: 1827). Precisamente, es ya en el siglo XXI, con la publicación de su novela Ocio (2000) y del volumen de cuentos Los Lemmings y otros (2005), que el nombre de Fabián Casas se despega de la masa generacional y alcanza una autonomía tan potente que se habla incluso de "Casas como la voz (una voz) representativa de su época" (Nimes, 2010: 1825).

Es cierto: en su literatura, Casas se trasunta o desplaza hacia un alter-ego visible, Andrés Stella, para hacerse de un locus de enunciación que trae aparejado un tono, una sintaxis y un estilo. "Esa voz imaginaria que construye su poesía, entonces, es una voz que aparece marcada con fuerza por la figura autoral” (2010: 1827), continúa Nimes. Y luego añade:

Una operativa cuyo rasgo principal sería el de la invisibilidad: el punto máximo de esplendor se alcanzaría cuando la "soldadura", el trabajo intertextual de remisión y reescritura, se vuelve imperceptible. Casas, entonces, se torna el poeta de lo imperceptible, el que juega y hace uso de diversos textos de (también diversas) tradiciones, dotando a lo ajeno de un fraseo tan propio que los Otros parecen disolverse y esfumarse en su propia voz. (2010: 1830)

\footnotetext{
${ }^{1}$ Para profundizar en la contraposición de estos dos paradigmas poéticos, puede revisarse los análisis que hacen Moscardi (2013) y Masiello (2012) de la obra de Fabián Casas.
} 
Sin embargo, si se analizan con cuidado sus treinta años de producción literaria, se advierte que el espacio de convocatoria de referencias de la alta cultura y de la cultura de masas actúa como mero contenido manifiesto o punto de llegada. Dichas referencias serían los nodos de un tejido elaborado a partir de objetos que tienden a volverse fetiche (los discos y sus carátulas, los libros y sus portadas, las películas y sus carteles), unidos por un material más delicado, menos visible, que se desliza por sus páginas como una "laminilla" que va de un nodo a otro y con extremo cuidado, al tener, por naturaleza, dicha "laminilla" una fragilidad evidente. Esa fragilidad radica, justo, en los afectos inconfesables y en la capacidad (fútil) de traer al presente un pasado que, a ratos, se conjuga en los textos de Casas como en las coplas de Jorge Manrique.

"Los relatos de Casas se entregan a la certidumbre del poder evocativo de las palabras, confían en la potencia de un conjunto de contraseñas para disparar el recuerdo" (2012: 117), señala Rodrigo Caresani:

[S]e saturan de referencias, apilan en un magma sin jerarquías una sucesión de guiños fáciles a la cultura de masas junto a los restos desauratizados de la Cultura - magma en el que, por un acto de prestidigitación lingüística, "Austerlitz", el personaje de la novela de W. G. Sebald, puede devenir "Asterix", el héroe de las historietas cómicas-. Pero lo que le está impedido a los textos es la puesta en secuencia de esos materiales: estos fetiches verbales se mantienen exteriores al relato. (2012: 117)

Pero, ¿son realmente exteriores al relato?, ¿no estarán formando todo esos Austerlitz (high)/Asterix (low), que saturan sus textos, una suerte de blindaje para disfrazar otra cosa?

El punto de partida de este ensayo es una discusión con Nimes, Caresani y otros críticos de la obra de Casas que, me parece, reconocen bien el recubrimiento posmoderno de la citación y la amalgama cultural, pero no alcanzan a dimensionar el alcance real de los cimientos de su proyecto literario. Con ayuda de algunas nociones de la crítica literaria contemporánea, y sobre todo del psicoanálisis, en este ensayo propongo analizar la novela Ocio, aunque haciendo también referencia a otros eslabones de su producción, bajo la siguiente premisa: los objetos presentes en las narraciones de Fabián Casas operan en un nivel empírico (permitiéndole a varios de sus personajes un "habitar" más amable de los espacios, re-territorializando de manera subjetiva los ambientes ya dados), pero también a un nivel sublime (actuando como fetiche, es decir, como fachada para desviar de sí un contenido más complejo y hasta dañino: el recuerdo de la madre muerta, en Ocio, por ejemplo, o el de un amigo perdido en las drogas, en la sección "Apéndices al Bosque Pulenta", de Los Lemmings y otros). Si para Caresani esos "fetiches verbales se mantienen exteriores al relato" (2012: 117), en mi análisis propongo que están en el epicentro de los mismos, lo que les permite funcionar como una evocación tramposa o "desplazada", con el fin de no enfrentar lo que, ulteriormente, resultará inevitable.

\section{Un cerco a lo indecible: aproximaciones teóricas}

Podríamos decir, de entrada, que la "forma" literaria de Fabián Casas va desde las pérdidas (la madre, los amigos, la infancia) hacia los objetos; por tanto, trabajará dichos objetos (libros, discos, revistas, películas, drogas) en tanto fetiches, articulando un relato con cierta pátina 
melancólica, propia de esta sublimación, pero que se interrumpe (o como critica Caresani no alcanza a "ponerse en secuencia" [2012: 117]), no por ineptitud narrativa, sino para evitar enfrentarse al intolerable dolor personal y familiar (o, en clave psicoanalítica, enfrentarse al das Ding ["la Cosa"]).

Expliquemos con detenimiento esta cuestión. En varios momentos de su obra, Jacques Lacan hace una interpretación del arte y la literatura como giros en torno a "la Cosa" (das Ding, en el término alemán). Con el propósito de configurarse en tanto sujeto social (la recurrente noción de \$, que se lee como "sujeto barrado"), el individuo es obligado a renunciar a la madre, alejándose del campo de "lo Real", lo que lo convierte en un ser deseante (de un afecto primario: el deseo por la madre, traducido luego como objet petit autre u objeto- $a^{2}$ ). Al estar socialmente penalizado desde lo "Simbólico" (o Ley-del-Padre), dicho deseo se reprime, pero es recursivo y al aparecer puede percibirse como amenazante y hasta desestructurante de la personalidad. "La Cosa", entonces, alude a un núcleo primario, complejo y traumático, que tiene una fuerte relación con el objeto perdido y que, al tratar de manifestarse, puede provocar dolor y hostilidad: "Das Ding es originalmente lo que llamaremos el fuera-de-significado", dice Lacan en El seminario 7: "En función de ese fuera-de-significado y de una relación patética con él, el sujeto conserva su distancia y se constituye en un modo de relación, de afecto primario, anterior a toda represión" (2011a: 70). Al estar en el campo de "lo Real", el das Ding no puede ser representado, debido a que remitiría a ese Otro absoluto (la madre), pero se regresa a él en términos de sublimación. Lo que haría el arte, entonces, al no poder darle materialidad semiótica, es "cercar" a "la Cosa", representando, digamos, su ausencia: "Ciertamente, las obras de arte imitan los objetos que ellas representan. Dando la imitación del objeto hacen del objeto otra cosa. De este modo sólo fingen imitar. El objeto está instaurado en cierta relación con "la Cosa" destinada a la vez a delimitarla, presentificarla y a ausentificarla" (Lacan, 2011a: 174).

Esto, por supuesto, solo es posible de hacer ver, en cualquier análisis, si se atiende al "trabajo del relato", a su forma de enunciación y a sus recurrencias, lo que es, en pocas palabras, equivalente al modo en que se desmonta el "trabajo del sueño". Lo que importa, además de descubrir un "núcleo" oculto y revelador de sentido para el sueño, es el trabajo que convirtió a ese sueño en una "forma" de pensamiento latente: el fetiche. Analizar, pues, implica "desfetichizar" el objeto para llegar a su proceso de elaboración, metodología que será útil para complementar de modo más hondo lo que otros críticos han dicho sobre la narrativa de Fabián Casas. Iremos, pues, de los objetos de Ocio a una aproximación potentísima del das Ding, haciendo el procedimiento a la inversa de lo que la crítica ha hecho con sus narraciones.

\footnotetext{
${ }^{2}$ Para Lacan, este objet petit autre (objet-a) indica la primera falta. Como el niño no tolera haberse separado de la madre, utiliza determinados elementos u objetos para volver a conectarse con dicha "totalidad" perdida, aunque sea parcialmente. El objeto-a no aparece y desaparece: lo llevará el sujeto toda su vida (desde la manta para dormir hasta, luego, un fetiche o un ideal de persona). Por ende, este objeto-a está vacío y se va llenando y vaciando continuamente, lo que explica, además de la dinámica del deseo (en tanto pulsión recurrente), fenómenos como el enamoramiento o la vocación artística. Es lo que se llama "significante vacío", muy importante en Lacan. Por lo tanto, un sujeto "evoluciona" al territorializar — centrar, establecer - su libido y al renunciar a su primer objeto de deseo (madre) para alinearse según la regulación de un "principio de realidad" (el padre). Un tránsito, pues, y ahora para hablar con propiedad lacaniana, del Cuerpo-de-la-Madre hacia el Nombre (o Ley)-del-Padre. Cf. Jacques Lacan, El seminario 11. Los cuatro conceptos fundamentales del psicoanálisis (2012).
} 
La conversión del contenido manifiesto del sueño en pensamiento onírico latente, en Freud, es lo que permite hablar de fetiche como una forma articulada a partir de un resto secreto que se deriva tras dicha conversión. Diríamos, siguiendo a Lacan, que aunque el procedimiento se hace evidente en la "forma", no acaba de revelarse. Es decir, y en clave lacaniana, el sujeto no consigue simbolizar - poner en palabras, encuadrar, hacer suyo- por completo este deseo atávico. De ahí que notemos que los objetos, en Fabián Casas, tienen una suerte de doble registro: por un lado, parecen ser simplemente mercancía cambiable; pero, por otro, están cargados de un carácter sensual, abstracto, representativo de otra cosa. Esa "otra cosa" es indecible, se escurre, y hace pensar en, precisamente, algo que se encuentra en el registro de "lo Real".

\section{Los objetos encubridores en Ocio}

En su totalidad, la novela Ocio se construye a partir de una analepsis hacia un pasado muy inmediato, en donde se darán las claves para comprender por qué el protagonista-narrador, Andrés Stella, después de un pasado errabundo, decide recluirse en su habitación y desde ahí rememorar esta historia: "[C]uando salí de la secundaria, me anoté en la Facultad de Filosofía. Cursé tres años y me fui dos de viaje. Cuando volví, al poco tiempo, murió mi mamá y mi familia se desintegró" (Casas, 2012: 14). ${ }^{3}$

Desde la primera página, Andrés articulará una enunciación anclada en un tiempo y un espacio permanentes: "Son las seis de la tarde y ya se pone oscuro. Estoy tirado en mi pieza, escuchando Abbey Road, de Los Beatles" (11). Esas seis de la tarde de un día indefinido de 1986, en el barrio de Boedo de la ciudad de Buenos Aires, representarán el punto de fijeza desde el cual la novela, hasta su última página, realice graduales saltos al pasado que irán definiendo con insistencia un "retorno" hacia algo cada vez más profundo. "Ayer hice casi lo mismo. Me levanté al mediodía, almorcé con mi viejo y mi hermano, porque era domingo y estaban en casa" (11-12. La cursiva es mía), puede leerse al comienzo, en una analepsis muy próxima; "Durante mi adolescencia tuve trabajos adicionales" (14. La cursiva es mía), señala Stella más adelante, dilatando la temporalidad y, por ende, materializando un recuerdo más difuso; hasta llegar, finalmente, a remembranzas que "cercan" al das Ding, como: "Mi mamá murió en mayo del 85, de un ataque de hipertensión arterial" y "[...] no volví a tomar drogas hasta el comienzo del invierno pasado, después de la muerte de mi vieja" (13. La cursiva es mía), que funcionan como punto de origen de la enunciación pero que intentarán ser contravenidas y desviadas a través de la aparición de los comentados objetos-fetiche.

Aunque más adelante veremos cómo Stella le hace finta a "la Cosa", debemos señalar que el marco de análisis antes enunciado no es gratuito, ya que el propio narrador de Ocio parece haber hecho consciente la situación, en tanto oquedad, que se vive en su casa desde 1985: "Mi vieja era el cruce de caminos donde nos encontrábamos. Era el motor. Una familia necesita siempre de un motor; porque si no es evidente la parálisis que se forma cuando varias personas se amontonan por mandatos biológicos" (13).

\footnotetext{
${ }^{3}$ De aquí en adelante, cada referencia al Ocio de Casas se refiere a la misma edición de 2012.
} 
Narratológicamente hablando, el inicio de Ocio es también su final. Stella recordará a partir de ahí, desde las seis de la tarde en Boedo, un día de invierno, todos los episodios que articularán la novela, pero esta no progresará más allá de esa instancia. Se trata, por ende, de un individuo que está reaccionando de manera ulterior ante un hecho (la muerte de la madre), asumiendo su cuarto como un espacio de cobijo:

Me imagino a las familias alrededor de las mesas, preparadas para cenar, con hogares encendidos y los leños quemándose en su felicidad. Las rutinas cotidianas del verano modificadas hasta el próximo año.

Pero no para mí: yo estoy, desde hace meses, hundido en el ocio. Como, cago, duermo; soy una biología que no tiene rumbo. (11. La cursiva es mía)

A partir de esas tres funciones biológicas podemos suponer que el protagonista experimenta en su cuarto la regresión a una etapa lactante — casi pre-edípica o pre-simbólica-: comer, defecar y dormir de manera espontánea, como lo hace un bebé que tiene una madre que lo asiste. Pero ante la ausencia de esa madre, Andrés Stella se retrotrae y asume la cama y la casa como los primeros objetos a los que aferrarse de manera sublime. En ese sentido, la casa en Ocio opera justo al revés que la del cuento "Casa tomada", de Julio Cortázar. Mientras que en este relato los hermanos se sienten acechados por las presencias que, paulatinamente, "toman" el hogar (materializadas a partir de ruidos cada vez más intolerables), en la novela de Casas hay un silencio general que invita a Andrés a no abandonar ni siquiera su cuarto: "En casa [su hermano] casi nunca hacía ruido y si hablaba era solamente porque todavía no había conseguido manejar la telepatía" (22). Es más: en los escasos momentos en los que aparecen ciertos sonidos, estos se integrarán de manera amable al ritual del ocio: "Durante las noches, la madera de la casa chirriaba contraída por el calor abrasador de la tarde. Era un concierto extraño. Me duchaba y me tiraba mojado en la cama a escucharlo" (64).

Esta fortísima inclinación del personaje hacia la reclusión se muestra ya de manera explícita cuando Andrés Stella, después de haber visto Led Zeppelin: The Song Remains the Same (Peter Clifton, Joe Massot, 1976); de haber robado libros y conversado con una serie de amigos poetas en el bar Astral, cae enfermo. Es decir, dichas correrías nocturnas lo harán somatizar (se resfría, tiene fiebre) para, así, evitar salir de casa: “Al día siguiente amanecí con una gripe mortal. Me dolía la garganta y tenía los ojos hinchados. Me miré en el espejo de la pieza: parecía que había estado peleando, con las manos atadas, contra Tyson" (31). La comparación no es antojadiza. Visualizarse en un espejo como una víctima disminuida ante un boxeador dos veces campeón del título de los pesos pesados ayuda a comprender la visión que Andrés tiene de la calle (un rival exterior y amenazante) y de la casa (un territorio interior que sustituye, poco a poco, la protección materna).

Estamos, por supuesto, hablando de los momentos iniciales (que a la vez, son los finales) de Ocio. En lugar de un exterior, que relaciona con su hermano y, sobre todo, con su padre ("Un tipo de la noche, de la farándula. Siempre se va después de cenar y vuelve a las seis de la mañana" [14]), Andrés prefiere quedarse instalado en esa suerte de nuevo útero (su pieza), con objetos específicos que le permitirán sublimar de manera amable el acercamiento al das Ding (los 
discos de Frank Zappa y Spinetta, y sobre todo Viaje al fin de la noche, de Céline). Las siguientes citas no hacen más que confirmarlo: "Me comí las lentejas, tomé un café, un Rexodón, un Refrianol y dos cafiaspirinas. Después pasé la tarde escuchando música: Abbey Road, Manal, Spinetta" (26); "Volví a mi pieza, agarré el libro otra vez [Viaje al fin de la noche] y sólo bajé de la cama para cambiar los discos. Puse, de un saque, Rubber Soul, de Los Beatles; Ratas Calientes, de Frank Zappa; Zeppelin I y II; Desatormentándonos, de Spinetta y Let It Bleed, de los Stones" (33).

Sin duda, Viaje al fin de la noche es el objeto mayormente fetichizado de Ocio debido a que es robado de una librería. Esta novela está cargada subliminalmente no solo por su contenido literario, que por supuesto hechiza a Andrés Stella al punto de sinonimizar objeto-libro con autor real ("Como no podía dormir, agarré a Celine [sic] y lo terminé de un saque. Era increíble que alguien pudiera escribir así” [34. La cursiva es mía]), sino por el propio valor que le otorga en tanto artefacto sensual que opera en las dos direcciones narrativas antes descritas: ayuda, por un lado, a desviar la atención del vacío de la madre y, por otro, a establecer mayor complicidad con su comunidad de amigos poetas: "En la fila de autores extranjeros apareció un nombre que sólo había escuchado en boca de Picasso y de Roli. Celine [sic]. Viaje al Fin de la Noche. Lo saqué del estante. Tenía la tapa blanca, con la firma en dorado del autor. Lo abrí al azar y leí [...]. Me acordé que tenía el libro de Celine [sic] en la campera. Lo puse sobre la mesa. «Acabo de robarlo», dije. Dragón lo agarró, lo hojeó y me dijo que era un libro extraordinario" $(20,29)$.

Sin duda, puede hacerse una analogía intertextual entre el contenido de ese libro-fetiche que lee y el contenido de esos discos-fetiche que escucha, en un hogar vacío que lo cobija, pero para el propósito de este ensayo lo esencial es solamente hacer notar cómo ciertas expresiones coloquiales, como "de un saque", le confieren una tonalidad más amable a la enunciación narrativa, dando a entender el bienestar del reposo en casa.

Aunque hay intenciones de identificarse con el padre ("A su favor diría que siempre fue un hombre limpio y ordenado [...]. Y quizá a mí me pase lo mismo, porque heredé esa manía. Aún hoy, tirado en la cama, sin salir desde hace días, mi pieza conserva un orden impecable" [1415]), sin duda serán las rutinas y comportamientos de la madre las que Stella prefiere para "ubicarse" en todo ese entramado familiar que en 1985 se desestructuró. Esto queda claro en la emotiva escena en la que el padre también resiente la ausencia de la mujer, y le pide a Andrés que le haga compañía:

Preparo el té y vuelvo a la pieza. Me pongo del lado de la cama que ocupaba mi vieja. Haciendo un ruido insoportable, mi viejo toma el té a sorbos. Después deja la taza que humea, sobre la mesa de luz.

— ¿Te podés quedar un rato? - dice.

- Claro - le contesto. (16. La cursiva es mía)

No obstante, a medida que avanza la trama de Ocio, y que el personaje trabaja de manera más arriesgada las analepsis, nos damos cuenta que, un año antes, cuando la muerte de la madre estaba demasiado cercana, la calle sí parecía una posibilidad de eclipsamiento simbólico, de encuentro de fetiches, en contrapunto con la casa y la pieza, cómplices de una evocación terrible. 
Es lo que sucede con un objeto que se sublimará, trascendiendo su mero valor utilitario: el coche familiar. Señala el narrador, rememorando la carrera de su padre como representante de artistas:

Entonces mi viejo dejó de actuar para representar actores. Ahí le fue bien, le tocó un cómico que ahora es muy famoso y se compró esta casa, el auto y un equipo de alta fidelidad. Pero como mi viejo lleva una vida limitada porque no sabe manejar, el auto lo maneja mi hermano, que además trabaja y tiene plata para la nafta. Así que el auto es una pasión inútil. Aunque a veces lo uso. Si mi hermano está durmiendo o salió y lo dejó, me fijo si le queda nafta y doy unas vueltas, despacio, hasta que el tablero empieza a marcar que estoy en rojo. Se podría decir que utilizo el tiempo que mi hermano prefirió no usar. Y estaría bien. A mí manejar me tranquiliza. No me gusta correr o pegar frenadas para que los giles me miren. Me gusta deslizarme por la ciudad nocturna, mirar a los pocos que cruzan las calles a esa hora, pensar boludeces mientras espero en un semáforo. (12-13)

"El real lacaniano [...] es más aterrador que la realidad externa", explica Slavoj Žižek, "y ésta es la razón de que despierte: para eludir el Real de su deseo, que anuncia en el sueño aterrador. Huye a la llamada realidad para poder continuar durmiendo, para mantener su ceguera, para eludir despertar a lo real de su deseo" (2003: 75-76). Por tanto, en un primer momento, Andrés cree que salir de casa supondrá, en efecto, vivir una suerte de nuevo nacimiento o mejor vivencia del duelo. Ese recorrido "inútil" por las calles, con una sartreana "pasión inútil" que es el auto, implica un uso, diríamos, casi terapéutico del objeto, donde el deslizamiento por una ciudad que se reconoce preeminentemente de noche hace más llevadera la ausencia materna.

Por otro lado, dicho duelo se vive teniendo peripecias con amigos ${ }^{4}$ que, en $O c i o$, trasuntan sus nombres, así como los infrarrealistas se trasuntaban en realvisceralistas, en Los detectives salvajes de Roberto Bolaño. De esta manera, los nombres de Rodolfo Lamadrid, Daniel Dragón, Picasso y Roli tienen un anclaje en el mundo empírico para rememorar a aquellos poetas que fundaron, junto a Fabián Casas, la ya mítica revista 18 Whiskys: Daniel Durand, José Villa, Rodolfo Edwards, Darío Rojo, Juan Desiderio, Gerardo Foia, etcétera. Igualmente, así como Belano y Lima en la novela de Bolaño, Stella y Roli, que antes se agrupaban con los demás en el bar Astral para planear la revista que diera un carpetazo a la literatura argentina, acabarán en el negocio del tráfico de drogas, con consecuencias dañinas para la salud mental de ambos.

¿Qué es lo que, finalmente, lleva a Andrés Stella de la mesa del Astral al nido de su cama de adolescente? Existen dos posibles respuestas a esta pregunta liminar, y esas dos respuestas abren la puerta, también, a dos interpretaciones alternativas de la novela. La primera ya quedaba esbozada más arriba: parece que cada vez que Andrés sale de casa, su cuerpo somatiza: primero, enferma de gripe; luego, contrae una alergia que lo lleva a buscar un rápido tratamiento en un consultorio médico ("Hulk era un tipo normal al lado mío. Me hubiese llevado todos los premios en el baile de disfraces del Club Bristol" [61]); posteriormente, es atacado por un dolor de muelas que percibe como la señal definitiva: "[C]omo si fuera una alarma, una muela entró en actividad y me empezó a partir la cabeza. Fui a un dentista de la obra social de mi viejo y me la saqué"

${ }^{4}$ El tema de los amigos como coraza ante los embates de la vida se repetirá en Titanes del coco, cuando Stella menciona, en el cuento "Kiss contra los fantasmas II": "El mundo es un lugar hostil, quien opine lo contrario no sabe dónde está parado. Los amigos son un escudo contra esa hostilidad. Son como esas secciones especiales de los cables de alta tensión que logran contener la energía, diversificarla, metabolizarla” (Casas, 2015: 119). 
(64); y finalmente, cuando sea testigo de la muerte de Roli, su mejor amigo, enfermará de hepatitis: "A eso de las tres de la tarde empecé a tener chuchos de frío y, cuando fui al baño a hacer pis, largué un chorro de petróleo [...]. Era hepatitis: mucha agua y reposo total" (71-72). Con este periplo de cuatro tiempos, de la gripe a la hepatitis, se comprende plenamente el epígrafe de Robert Lowell que abre el libro: "In the end, every hipochondriac is his own prophet" (9), lo que invita a encontrarle otro significado a la novela. Ocio puede leerse, entonces, como la narración de un hipocondríaco que, debido a su sintomatología, decide abandonar el exterior y hacerse un nido puertas adentro.

La segunda razón es menos especulativa y emerge en la trama misma. El narrador le llama, de hecho, "la ascensión y caída del Príncipe Roli" (51). Se trata de los límites que, debido a su paranoia, el mismo Andrés Stella se autoimpone para el negocio del tráfico de drogas: "A veces teníamos plata y todo marchaba sobre rieles. De golpe quedábamos endeudados hasta la manija, porque nos habíamos tomado lo que teníamos que vender" (51); "Cuando uno está vendiendo, la policía se vuelve una obsesión. Yo los veía en todos lados: policías secretos, perros entrenados, micrófonos, la más alta tecnología organizada para llevarme a la cárcel” (52). Finalmente, será la testificación del daño que dichas drogas le provoquen a su amigo Roli, y una somatización intensa por ello, lo que lo haga abandonar la calle e instalarse en su habitación, con la rutina del ocio en plenitud:

Mientras atravesábamos la plaza — a la altura de la fuente de agua-, me dijo que se sentía mal: "Me parece que me voy a caer". Le dije que nos sentáramos en el piso. "No", dijo. "Tengo un montón de droga encima. Si me caigo vos seguís caminando y te vas". Le pregunté si estaba loco. "Estoy hiper lúcido", dijo en voz muy baja. "Mi corazón va a mil. Me estoy por ir definitivamente" [...]. Roli estaba definiendo a penales con Caronte. (62-63)

De alguna manera, este personaje de Roli — por su exuberante personalidad y por su trágico final- se condice con el personaje de Máximo Disfrute, de Los Lemmings y otros. ${ }^{5} \mathrm{Al}$ final de Ocio, Andrés Stella es informado por Picasso, su amigo del bar Astral, que Roli se encuentra hospitalizado. Bien vale la extensión de la cita, porque aquí la prosa de Casas aúna, de

\footnotetext{
${ }^{5}$ Roli ya había aparecido en Tuca ("También tuvimos una guerra/ Ahora somos parte de Hollywood./ Ese chico con la cabeza vendada,/ que antes era Roli,/ dice llamarse Apollinaire" [Casas, 2010: 13]) y tendrá, especulamos, su transfiguración definitiva en Máximo Disfrute, aunque no sus mismas circunstancias finales (Roli muere en la UCI de un hospital humilde; Máximo sobrevive a las adicciones): "Máximo Disfrute, mi primer amigo, maestro, instructor, como se le quiera llamar [...]. Máximo Disfrute empezaba a hacerse una reputación importante en todo Boedo [...]. Se empezó a correr la bola de que en una calle de Boedo había un chico, un tal Máximo Disfrute, que la rompía" (Casas, 2011: 43, 45-46), puede leerse en "El bosque pulenta", de Los Lemmings y otros. Más adelante en el mismo volumen, Casas incluirá "Apéndices al Bosque Pulenta", conformado por dos textos. En el primero, Máximo Disfrute se confesará con un doctor, en un monólogo interior divertido y angustioso a partes iguales ("M. D. divaga sobre un trastorno") y en el segundo, un antiguo compañero, el gordo Noriega (que también tiene aparición en Ocio, y una chica del grupo de Boedo, Pan Dulce, presenciarán su decadencia en televisión abierta ("El día en que lo vieron en la tele”): “¿Hola, Andrés?, digo. Sí, me contesta. ¿Tenés un televisor cerca? ¿Para qué, gordo?, me dice, y eso que ya no soy gordo, pero el hijo de puta me sigue diciendo gordo. Prendé el televisor, boludo, y buscá el noticiero, le grito. ¿Qué pasa, gordo? Pasa que está Máximo en la tele. ¿Máximo? Sí, él mismo, Máximo Disfrute. ¡Anda a la concha de tu madre, gordo! Seguramente está fumando porro. Desde que volvió de ese viaje lo único que hace es rascarse las bolas y fumar porro en la pieza que tiene en la casa de los viejos. Andrés, lo están entrevistando a Máximo, que es un drogadicto recuperado, ¡acá lo estoy viendo, boludo!” (140-141).
} 
manera prístina, las características antes enunciadas: el territorio de la mixtura cultural, donde la mención a películas, como la de Led Zeppelin, se vuelve objeto sublime (fetiche); la tonalidad poética de Tuca, El salmón y Oda, ahora en su narrativa; y la aproximación, por azoro, al das Ding donde los referentes ya no son capaces de aguantar el peso de las revelaciones:

Me acerqué lo más que pude [...] y lo miré fijo. Debo de haber estado así más de media hora. Su cara tenía una gran serenidad. Cada minuto de nuestra vida en común pasó por delante de los ojos de la mente. Durante los quince y los dieciséis habíamos ido puntualmente a la trasnoche del cine Lara a ver "La canción es la misma", de Led Zeppelin. Yo la había visto unas treinta y dos veces, Roli se jactaba de unas cincuenta. Cuando lo conocí, me preocupé por imitar su forma de caminar. También repetía sus expresiones, como "bardo catatónico" o "frío nival" o "me explota la cabeza". Se me ocurrió que en algún momento de ese pasado, en algún resquicio estaba el origen de lo que lo había postrado. Esa geometría invisible lo había puesto a él en la cama de un sanatorio y a mí a sus pies, parado. Yo estaba vivo y él a punto de partir. Esa era la moneda.

Me saqué el guante - tenía los ojos húmedos y me ardían-, le agarré la mano. Era un peso muerto, tibio. Y de golpe me acordé de mi vieja [...]. Mi mamá me saludaba agitando su brazo derecho. Estaba con su bata roja. Con el brazo izquierdo abrazaba a Roli. Los dos se reían de mí. (69-70)

Este párrafo del final de la novela funciona, sin duda, como gozne entre Ocio y Los Lemmings y otros (al menos, con el relato que le da nombre al volumen). Tras la convalecencia por la hepatitis — razón física - y por el duelo tras la muerte de Roli y su madre —razón interna-, Stella realizará todo un procedimiento para rehabitar la casa, "cercando la Cosa" a través de estos referentes y, de esta manera, desterritorializar, ${ }^{6}$ aunque sea mínimamente, el territorio que antes estaba bajo el imperio y recuerdo de su madre y, posteriormente, bajo el precario influjo de su padre: "La estrategia de mi viejo era reconstruir la familia a partir del almuerzo. Eso estaba claro [...], pero después mi viejo puso el televisor portátil y comíamos mirándolo y ya casi no hablábamos" $(36,42)$. Aunque Stella pueble dicha habitación con referentes culturales de su gusto, lo que acaba poniéndose delante de los ojos del lector es, otra vez, una regresión: este hipocondríaco que ha probado las drogas, el menudeo y las artes, retorna a su cuarto de niño para vivir la ilusión momentánea de ser cuidado por una madre ausente y sentirse otra vez conectado a una "totalidad" perdida.

Como ya se ha dicho, Ocio es una novela que se construye como una fuerza centrífuga alrededor de un vacío: el del Gran Otro absoluto, en términos de Lacan. La serie de objetos que

\footnotetext{
${ }^{6}$ Se emplea aquí el concepto de desterritorialización así como Gilles Deleuze y Félix Guattari lo ocupan, en Mil mesetas. Capitalismo y esquizofrenia. Es decir, y en consonancia con los términos rizoma y esquizo, dejar de ocupar geográficamente un cuerpo (biológico o social) según las pautas aprendidas por influencia del significante y volver a estratificarlo para conveniencia de los flujos vitales: "Todo rizoma comprende líneas de segmentaridad según las cuales está estratificado, territorializado, organizado, significado, atribuido, etc.; pero también líneas de desterritorialización según las cuales se escapa sin cesar. Hay ruptura en el rizoma cada vez que de las líneas segmentarias surge bruscamente una línea de fuga, que también forma parte del rizoma. Esas líneas remiten constantemente unas a otras. Por eso nunca debe presuponerse un dualismo o una dicotomía, ni siquiera bajo la forma rudimentaria de lo bueno y de lo malo. Se produce una ruptura, se traza una línea de fuga, pero siempre existe el riesgo de que reaparezcan en ella organizaciones que reestratifican el conjunto, formaciones que devuelven el poder a un significante, atribuciones que reconstituyen un sujeto: todo lo que se quiera, desde resurgimientos edípicos hasta concreciones fascistas. Los grupos y los individuos contienen microfascismos que siempre están dispuestos a cristalizar" (Deleuze, Guattari, 2012: 15).
} 
atrae el protagonista - y también los personajes secundarios, como el padre — ayudan a lograr un precario equilibrio para prevenir, lo más posible, una inminente crisis emocional. La madre opera aquí como el gran objeto sublime, que persiste más allá de la corrupción del cuerpo físico, en un recuerdo que insiste en aparecer, incluso cuando Andrés Stella desea sublimarlo a partir de su incipiente vocación de escritor. ${ }^{8}$ No es gratuito que justo cuando busca un cuaderno para comenzar a redactar los poemas que desea entregarle a Picasso para la revista que se planea en el Astral, de ese cuaderno caigan las fotos familiares, como señal de que el personaje parece irremediablemente inmerso en dicho bucle o ritornello del recuerdo materno:

Subí a mi pieza y empecé a buscar en las carpetas que tenía sobre el escritorio unas hojas en blanco. Buscaba un cuaderno que había comprado unas semanas atrás para conseguir cambio. Era un cuaderno horrible, con la foto de un motociclista en la tapa. De una de las carpetas se cayeron fotos donde mi vieja estaba en la terraza, al sol. Me parecieron de su último verano. Pero no lo podía asegurar: mi vieja no había cambiado mucho en los últimos años. Tampoco podía recodar quién me había dado esas fotos. Las guardé en un sobre y seguí buscando el cuaderno. (37)

De esta forma, comprendemos que los personajes se ayudan con los objetos a reprimir un contenido traumático, pero al final dicho contenido siempre regresa. Si en un comienzo la madre vuelve como un destello momentáneo y consciente, se materializará luego icónicamente en unas fotos que aparecen de repente, hasta ocupar, bajo la historia manifiesta de un sueño, la totalidad de la existencia psíquica de Stella. Por eso en el segundo momento en que halla las fotos, ya el desmoronamiento emocional es inevitable. ${ }^{9}$ De esta forma, entonces, el coche que maneja despacio por Boedo, las drogas cada vez más duras, los discos de Spinetta y Frank Zappa, la película de Led Zeppelin y el libro de Louis-Ferdinand Céline resienten su posibilidad de erigirse como fetiches sublimes, y será a través de la convalecencia de las distintas enfermedades que lo aquejan que aprenderá a volver a habitar la casa materna, ahora con una suerte de agujero o hiancia (para usar el nombre técnico del psicoanálisis para designar la abertura ominosa dejada por "lo Real" en el sujeto) enorme en su centro.

Pudiera parecer que muchos de los objetos en la novela de Casas están condenados a un fracaso evidente: simbolizar "lo Real". Pero en realidad tienen una funcionalidad social y primigenia: impedir que los personajes caigan en dicho agujero. Los objetos, desde los pequeños

\footnotetext{
7 “Abajo, en el patio cubierto, mi viejo se paseaba en pijamas. Envejeció en estos últimos meses como un millón de años. Yo lo miraba a través de las rendijas de la ventana de mi pieza. Estaba encuadernando revistas. Siempre compró cualquier cantidad de revistas. Colecciona enciclopedias sobre perros, ocultismo, historia, depilación a la cera negra; en la terraza hay un cuarto lleno de revistas" (Casas, 2012: 12).

${ }^{8}$ Es más: hay un momento en que la sublimación parece consciente, al escribir, precisamente en el cuaderno donde encuentra las fotos, un poema que supondrá el mayor acercamiento voluntario hacia ese "agujero negro" que supone el das Ding: "Agarré una hoja más y escribí: «Madre/ llegaron los huecos feroces de tus soles/ los látigos de la muerte/ toda esa oscuridad que no puede acabarte/ ahora que tu corazón late al revés/ dando golpes de frío y de cuchillo" (38).

9 "Busqué en los cajones una caja donde tenía fotos familiares. A veces me daban ganas de mirarlas. Cuando las encontré las volqué: mi mamá, mi papá, mi hermano y yo, en malla, en Mar del Plata [...]. En otra, mi vieja secaba a un perro que habíamos tenido. Ella era la única que lo bañaba y después lo secaba en la terraza. La fotografía es una de las cosas más crueles que existen. Es un invento satánico. El perro, con el pelo húmedo, miraba a la cámara. Me quedé mirando la foto hasta que se me humedecieron los ojos. Entonces apagué la luz, me tiré en la cama y me puse a llorar como un hijo de puta" (50).
} 
y tangibles hasta los monumentales y abstractos, alimentan un mayor y sublime objeto de la ideología, que es la recuperación del pasado donde estaba la madre y la posibilidad de que ese pasado encaje, de manera amable, en el presente de aquellos tres varones. De esta forma, al pasar una y otra vez por los mismos lugares, el retorno materno va generando, y volviendo a la teoría lacaniana, un fantasma, ${ }^{10}$ no solo en su acepción intermitente de presencia-ausencia, sino como encuadre para que los hombres puedan empezar a funcionar, en esa casa, como una familia reconfigurada.

En Los Lemmings y otros, Casas repetirá varias de las estrategias narrativas de Ocio, aunque las historias allí no se articulen alrededor del vacío de la madre, sino de la pérdida abrupta de la infancia. ${ }^{11} \mathrm{Al}$ respecto, señala Caresani que: "[L]os relatos prometen esa intensidad sorpresiva del final, pero la promesa o bien no se cumple o se articula débilmente. El giro, esa «inminencia del cierre» [...] en que la narración decide el sentido y encuentra su forma, se plantea como una expectativa constantemente frustrada" (2012: 115). No obstante, con ayuda del marco psicoanalítico y no solo narratológico, ahora se comprende la funcionalidad de esa impresión. Aunque el relato intente enunciarse con vigor, algo ocurre que provoca la ruptura de la expectativa inicialmente planteada. Siempre hay algo que se escurre, un plus que escapa a la simbolización. Caresani lo critica desde el punto de vista estructural-narrativo, pero para este análisis resulta casi lógico: el lenguaje no llega a capturar el núcleo primario materno, y por eso

\footnotetext{
${ }^{10}$ Siguiendo a Lacan, "el fantasma es el soporte del deseo, no el objeto" (2012: 192). Expuesta en diversos momentos de su trabajo, la función del fantasma consiste en lo siguiente: cuando todo individuo insiste en una demanda, ya sea a través de actos verbales o no verbales, se debe a que su pulsión va en pos de un objeto que no consigue realmente y que, por tanto, solo rodea. La pulsión, en tanto tendencia poderosa, ingobernable y, por lo tanto, presencia de Otro que actúa o dice, no satisface el deseo, sino solo se satisface a sí misma. Debido a que, en el recorrido de la demanda al objeto, la pulsión pasa una y otra vez, aparece un fantasma (indicado con la fórmula $\$ \diamond$ a. \$, como se vio más arriba, es el sujeto barrado por la ley del lenguaje significante; $\diamond$ (losange) significa implicación recíproca de los términos; y $a$, "autre" en francés, es el objeto-otro u objeto- $a$, que en posición inconsciente no se trataría de un objeto que se desea conscientemente, sino aquello que el objeto representa (la voluntad de volver a estar conectado con aquel Cuerpo-de-la-Madre, es decir, con la totalidad perdida). Sin fantasma, dice Lacan, el sujeto no podría enmarcar su relación con el mundo. $C f$. Lacan, ; y "El obsesivo y su deseo", en El seminario 5: Las formaciones del inconsciente: "La relación con la imagen del otro, i(a), se sitúa en una experiencia integrada en el circuito primitivo de la demanda, en el cual el sujeto se dirige en primer lugar al Otro para la satisfacción de sus necesidades. Es, pues, en algún lugar de este circuito donde se produce la acomodación transitivista, el efecto de prestancia que pone al sujeto en una determinada relación con su semejante como tal. La relación de la imagen se encuentra así en el nivel de las experiencias e incluso del tiempo en que el sujeto entra en el juego de la palabra, en el límite del paso del estado infans al estado hablante. Una vez establecido esto, diremos que en el otro campo, allí donde buscamos las vías de la realización del deseo del sujeto mediante el acceso al deseo del Otro, la función del fantasma se sitúa en un punto homólogo, es decir en $(\$ \diamond a)$. El fantasma lo definiremos, si les parece, como lo imaginario capturado en cierto uso del significante" (2010: 416-417).

${ }^{11}$ En el cuento que da título al volumen, las analepsis van más atrás de 1985 y se instalan en los años setenta. Allí la madre todavía es una presencia muy activa en Andrés Stella, al punto de vulgarizarla, socarronamente, para ponerla a distancia en su pubertad: "Tenía un hermanito en tercer grado, su padre era taxista y su madre era gorda, jcomo la mía!" (Casas, 2011: 14). Lo que tenemos en este relato, "bisagra" entre la novela Ocio y el volumen de cuentos que se abre, es la posibilidad, consciente por primera vez, de la elección de objeto de deseo en Andrés para salirse

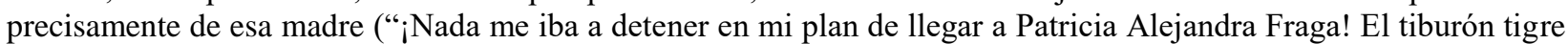
anda siempre nadando a ras del fondo" [18]); pero, ante todo, una celebración elegiaca de un entorno de amistad interrumpido por las crisis de finales de los años setenta y principios de los ochenta en Argentina: "El tano Fuzzaro, el japonés Uzu, inventor del Boedismo Zen, los chicos del pasaje Pérez, los hermanos Dulce... Muchos borrados antes de tiempo con el liquid paper del Proceso, las Malvinas y el sida...” (19-20).
} 
se trabaja con elipsis, interrupciones, apenas roces al tema. "Sé que estas palabras suenan a la basura de la autoayuda", dice el propio Casas, "pero no puedo expresarme mejor y les pido disculpas. Tal vez deba pasar de nuevo de lo abstracto a lo concreto" (2010: 197-198).

Adicionalmente, y trabajando a la inversa, "desfetichizando" los objetos, ya entendemos que Casas articula el relato en una posición intermedia entre lo que se dice y se omite, lo que se olvida y se recuerda, entre las asociaciones que genera, las resistencias al recuerdo y las pretensiones de ocultamiento del dolor personal.

\section{Bibliografía}

BRESCIA, Pablo: "Fabián Casas, La supremacía Tolstoi y otros ensayos al tuntún”. Revista Acta Literaria 50 (enero-junio 2015): 155-158. DOI: https://doi.org/10.4067/s0717$\underline{68482015000100009}$

CARESANI, Rodrigo Javier: "Nuevos realismos en la escena literaria argentina: Fabián Casas versus Martín Rejtman”. Revista Texturas. Estudios Interdisciplinarios sobre el Discurso 12 (2012): 111-128. DOI: https://doi.org/10.14409/texturas.v1i12.2914

CASAS, Fabián (2010): Horla city y otros. Barcelona: Seix-Barral.

--- (2011): Los Lemmings y otros. Barcelona: Alpha Decay.

--- (2012): Ocio. Barcelona: Alpha Decay.

--- (2015): Titanes del coco. Buenos Aires: Emecé.

DELEUZE, Gilles y Félix GUATTARI (2012): Mil mesetas. Capitalismo y esquizofrenia. $10^{\mathrm{a}} \mathrm{ed}$. Valencia, Pre-Textos.

LACAN, Jacques (2009): El seminario 10. La angustia. Buenos Aires, Paidós.

--- (2010): El seminario 5. Las formaciones del inconsciente. $9^{\mathrm{a}}$ ed. Buenos Aires, Paidós.

--- (2011a): El seminario 7. La ética del psicoanálisis. 12a ed. Barcelona, Paidós.

--- (2011b): "Función y campo de la palabra y del lenguaje en psicoanálisis". Escritos 1. $1^{\mathrm{a}}$ reimp., $3^{\mathrm{a}}$ ed. México, Siglo XXI: 231-310.

--- (2011c): "Subversión del sujeto y dialéctica del deseo en el inconsciente freudiano". Escritos 2. $1^{\mathrm{a}}$ reimp., $3^{\mathrm{a}}$ ed. México: Siglo XXI: 755-788.

--- (2012): El seminario 11. Los cuatro conceptos fundamentales del psicoanálisis. $19^{\mathrm{a}}$ reimp., $1^{\mathrm{a}}$ ed. Buenos Aires, Paidós.

MASIELLO, Francine: "Cuerpo y materia: una lectura de la poesía contemporánea argentina". Revista de Crítica Literaria Latinoamericana XVIII/76 (2012): 143-172.

MOSCARDI, Matías: "Poesía argentina de los noventa: escrituras artesanales". Cuadernos de Literatura XVII/34 (julio-diciembre 2013): 106-121.

NIMES, Daniel (2010): "La voz extraña: Fabián Casas y la construcción de una voz generacional". Memorias del IV Congreso Internacional de Letras. Ed. XY. Buenos Aires, Facultad de Humanidades, Universidad Nacional de Mar del Plata: 1825-1832. 
ŽIŽEK, Slavoj (2003): El sublime objeto de la ideología. Buenos Aires, Siglo XXI.

(C) Felipe Adrián Ríos Baeza

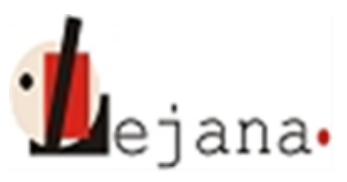

http://ojs.elte.hu/index.php/lejana

Universidad Eötvös Loránd, Departamento de Español, 1088 Budapest, Múzeum krt. 4/C 